week. Soya bean curd, which is an important potential source of calcium in the Chinese diet, was eaten at least once a week by $35 \%$ of controls but by only $27 \%$ of patients. In contrast to the data from Southampton, calcium was found to protect against fracture in both women and men. In the past low calcium intake might have been offset by a high level of weight bearing physical activity, which maintained bone mass. The decline in activity which followed the construction of high rise apartments and the disappearance of walking space may have unmasked the adverse skeletal effect of a low calcium intake.

Public health strategies to reduce the rising incidence of hip fractures in urbanising oriental populations are urgently required. Our results point to the importance of maintaining physical activity and calcium intake in elderly Chinese people who grew up in rural communities, characterised by high levels of physical activity and a diet low in calcium, but are now mostly living in flats in high rise buildings while continuing to eat a traditional diet.

This study was supported by a grant from the Wellcome Trust. We acknowledge Dr Y Chow and Dr D Lau of Queen Elizabeth Hospital and Dr P C Lee of Kwong Wah Hospital for their help in recruiting patients. We thank Miss R To and Mrs F Cheng, who interviewed the subjects; Mr A Cheang, who helped with the analysis; and Mrs P Tam and Mrs B Wilde for the secretarial support.

1 Lau EMC, Donnan SPB. Physical labour and fractured proximal femur in Chinese. Am J Epidemiol 1987;126:753.

Pun KK, Young RTT. Osteoporosis - the silent epidemic. JAMA (South East Asian edition) 1987; Oct:5-6.

3 Food and agriculture organisation. Food composition table for use in East Asia. Rome: FAO, 1972 .

4 Chalmers J, Ho KC. Geographical variations in senile osteoporosis. The association with physical activity. I Bone foint Surg $[B r]$ 1970;52:667-75.

(Accepted 20 September 1988)

\title{
Physical activity, muscle strength, and calcium intake in fracture of the proximal femur in Britain
}

\author{
C Cooper, D J P Barker, C Wickham
}

\begin{abstract}
Regular exercise and high calcium intake possibly help to preserve bone mass. Little is known, however, about their role in preventing hip fracture. The physical activity and calcium intake of $\mathbf{3 0 0}$ elderly men and women with hip fractures were compared with those of $\mathbf{6 0 0}$ controls matched for age and sex. In both sexes increased daily activity, including standing, walking, climbing stairs, carrying, housework, and gardening protected against fracture. This was independent of other known risk factors, including body mass, cigarette smoking, and alcohol consumption. Strength of grip correlated with activity and was inversely related to the risk of fracture. Calcium intake was not related to the risk of fracture in women. Men with daily calcium intakes above $1 \mathrm{~g}$ had lower risks.

These findings point to the importance of elderly people in Britain maintaining physical activity in their day to day lives.
\end{abstract}

\section{Introduction}

Hip fractures in elderly people are an important public health problem. Osteoporosis and falls are two known aetiological factors. ${ }^{1}$ Regular exercise and high calcium intake, measures that possibly preserve bone mass, ${ }^{2}$ offer the main immediate population based strategy for preventing osteoporosis. Little information, however, is available about their role in preventing hip fracture, ${ }^{3}$ and hence no scientific basis exists for recommending them as part of a national preventive campaign. We used validated methods to compare physical activity and calcium intake in a series of elderly patients with hip fractures and community controls. We measured the independent contribution of each of these two factors to the risk of hip fracture after allowing for the confounding effects of other known risk factors, which include low body mass, cigarette smoking, and alcohol consumption. ${ }^{3}$

\section{Patients and methods}

We recruited 473 patients aged 50 and over who lived in Southampton health district and were admitted sequentially to the orthopaedic wards of this hospital. Fifteen patients died before they could be approached, and 12 declined to participate. The remaining 446 completed a 10 point Hodkinson abbreviated mental test score, ${ }^{+}$and the 300 patients ( 240 women and $60 \mathrm{men}$ ) who scored more than 6 became the study group. We estimated that a study of this size had a $90 \%$ power of detecting a relative risk of 1.7 or more in women and 3.0 or more in men at the five per cent level of significance, assuming a $30 \%$ exposure of the controls to a dichotomous risk factor.

Patients in the study group were compared with 600 community controls, resident in the same district, who were selected from the register of Hampshire Family Practitioner Committee. Controls were individually matched to the patients in the study group by sex and age within four years. The rate of response among controls was $71 \%$ of those contacted. When a control refused to participate or failed the mental test score a substitute was selected.

All patients in the study group and the controls were interviewed by one of three trained interviewers. Each case-control set was seen by the same interviewer. Patients were interviewed in hospital within ten days of admission. Controls were interviewed within three months of their matched patient $(68 \%)$ or during the corresponding quarter a year later (32\%).

Physical activity in the six weeks before the interview was estimated with a validated questionnaire for the assessment of customary activity in the elderly. ${ }^{5}$ Five indices of current activity were derived: self reported walking speed, time spent standing indoors, time spent walking outdoors, frequency of muscle loading activity such as climbing stairs or carrying loads, and time spent in productive activities such as gardening and housework.

Current calcium intake was measured with a frequency and amount questionnaire, which obtained information about the consumption of six food items: milk, bread, cheese, puddings, cakes, and biscuits. A Department of Health survey of elderly people in Britain suggested that $87 \%$ of their total calcium intake was derived from these food items. ${ }^{6}$ We have shown previously that estimates of calcium intake with this questionnaire correlate well with those derived from 
duplicate diet analysis and six day weighed inventories. ' The strength of grip was measured with an isometric dynamometer. The maximum of three

TABLE I - Distribution of 446 patients with hip fracture by age, sex, and mental test score

\begin{tabular}{|c|c|c|c|c|c|c|}
\hline \multirow[b]{3}{*}{ Age (years) } & & & \multicolumn{4}{|c|}{ Mental test score } \\
\hline & \multicolumn{2}{|c|}{ All } & \multicolumn{2}{|c|}{$>5$} & \multicolumn{2}{|c|}{$\leqslant 5$} \\
\hline & Women & Men & Women & Men & Women & men \\
\hline$<55$ & 3 & 6 & 3 & 6 & & \\
\hline $55-$ & 12 & 9 & 11 & 8 & 1 & 1 \\
\hline $65-$ & 55 & 18 & 50 & 16 & 5 & 2 \\
\hline $75-$ & 142 & 30 & 99 & 22 & 43 & 8 \\
\hline$>84$ & 155 & 16 & 77 & 8 & 78 & 8 \\
\hline Total & 367 & 79 & 240 & 60 & 127 & 19 \\
\hline
\end{tabular}

TABLE II -Distribution of risk factors for hip fracture among 300 patients with hip fracture and 600 matched controls

\begin{tabular}{|c|c|c|c|c|}
\hline Variable & $\begin{array}{c}\text { No }(\%) \text { of } \\
\text { patients }\end{array}$ & $\begin{array}{l}\text { No (\%) of } \\
\text { controls }\end{array}$ & Relative risk & $\begin{array}{c}95 \% \\
\text { Confidence } \\
\text { interval }\end{array}$ \\
\hline \multicolumn{5}{|l|}{ Body mass index $\left(\mathrm{kg} / \mathrm{m}^{2}\right)$ in fifths of distribution: } \\
\hline Lowest & $88(32)$ & $84(15)$ & $6 \cdot 7$ & 3.8 to 11.7 \\
\hline Second & $67(24)$ & $94(17)$ & $4 \cdot 3$ & $2 \cdot 4$ to $7 \cdot 4$ \\
\hline Third & $60(22)$ & $112(20)$ & $3 \cdot 3$ & 1.9 to 5.8 \\
\hline Fourth & $40(14)$ & $128(23)$ & $2 \cdot 1$ & $1 \cdot 2$ to $3 \cdot 8$ \\
\hline Highest & $24(9)$ & $144(26)$ & $1 \cdot 0$ & \\
\hline Cigarette smoking & $145(48)$ & $223(37)$ & $1 \cdot 7 \dagger$ & $1 \cdot 2$ to $2 \cdot 3$ \\
\hline \multicolumn{5}{|l|}{ Alcohol consumption: } \\
\hline Moderate or heavy & $28(9)$ & $12(2)$ & $7 \cdot 5$ & $3 \cdot 3$ to $16 \cdot 8$ \\
\hline Light & $108(36)$ & $205(34)$ & $1 \cdot 3$ & 1.0 to 1.8 \\
\hline Occasional or abstainer & $163(55)$ & $382(64)$ & $1 \cdot 0$ & \\
\hline History of stroke & $34(11)$ & $39(7)$ & $1 \cdot 8$ & $1 \cdot 1$ to $2 \cdot 9$ \\
\hline Current use of corticosteroids & $16(5)$ & $13(2)$ & $2 \cdot 7$ & $1 \cdot 2$ to $5 \cdot 8$ \\
\hline History of a fall in the previous nine months & $112(37)$ & $153(26)$ & 1.8 & $1 \cdot 3$ to $2 \cdot 5$ \\
\hline Previous hip fracture after age 50 & $37(12)$ & $14(2)$ & $6 \cdot 8$ & 3.4 to 13.8 \\
\hline Previous wrist fracture after age 50 & $48(16)$ & $52(9)$ & $2 \cdot 3$ & 1.4 to 3.6 \\
\hline \multicolumn{5}{|l|}{ Gait abnormality: } \\
\hline Walks only with help of another person & $32(11)$ & $23(4)$ & $4 \cdot 3$ & 2.4 to 7.9 \\
\hline Walks with stick & $126(42)$ & $199(33)$ & 1.9 & 1.4 to $2 \cdot 6$ \\
\hline Walks unaided & $142(47)$ & $377(63)$ & 1.0 & \\
\hline \multicolumn{5}{|l|}{ Mental test score: } \\
\hline 6 and 7 & $62(21)$ & $62(10)$ & $3 \cdot 1$ & 1.9 to 4.8 \\
\hline 8 & $36(12)$ & $60(10)$ & 1.6 & 1.0 to 2.5 \\
\hline 9 & $53(18)$ & $113(19)$ & $1 \cdot 2$ & 0.8 to 1.7 \\
\hline 10 & $149(50)$ & $365(61)$ & $1 \cdot 0$ & \\
\hline \multicolumn{5}{|l|}{ Dependence in daily living activities: } \\
\hline Requires help in three or more activities & $28(9)$ & $21 \quad(3)$ & $4 \cdot 4$ & $2 \cdot 3$ to $8 \cdot 4$ \\
\hline Requires help bathing and dressing & $38(13)$ & $34(6)$ & $3 \cdot 4$ & $2 \cdot 0$ to $5 \cdot 8$ \\
\hline Requires help bathing & $77(26)$ & $124(21)$ & 1.9 & 1.3 to $2 \cdot 8$ \\
\hline Fully independent & $157(52)$ & $420(70)$ & 1.0 & \\
\hline
\end{tabular}

*Information was not available for all subjects.

tRelative risk refers to that between those who had ever smoked and those who had never smoked. readings on each hand was used for subsequent analysis.

The data were analysed with a conditional logistic regression for matched case-control studies, which produced relative risks and $95 \%$ confidence intervals. ${ }^{8}$ The significance of gradients of relative risk was assessed with $\chi^{2}$ tests for linear trend. Relations between variables were studied with multiple linear regression or analysis of covariance.

\section{Results}

Table I shows the age and sex distribution of the 300 patients whose mental test score was over 5 and the 146 whose score was 5 or under. The 146 patients were older than the 300 , and their female to male ratio was greater. More of them were living in supervised accommodation (warden controlled flats, rest homes, and nursing homes).

Table II shows the distribution among patients and controls of variables found to be associated with risk of fracture. The risk declined progressively with rising body mass index and mental test score and increasing independence in daily living activities. The risk was increased by cigarette smoking, alcohol consumption, a history of stroke, current use of corticosteroids, a fall during the previous nine months, previous hip or wrist fractures, and inability to walk unaided.

No difference was detected in the mean age at menarche or the menopause of patients and controls. Eighteen of the women with hip fractures $(8 \%)$ and 22 female controls (5\%) recalled having had an oophorectomy, giving a relative risk of $1 \cdot 5$, which was not, however, significant at $\mathrm{p}=0.05$ (95\% confidence interval 0.9 to 3.2 ). The previous use of postmenopausal hormone replacement treatment was reported by six patients (3\%) and 23 controls (5\%), giving a relative risk of 0.5 , which again was not significant $(0 \cdot 2$ to $1 \cdot 3$ ).

\section{PHYSICAL ACTIVITY}

We analysed the risk of hip fracture in relation to each of the five indices of current physical activity (table III). Among women the risk of fracture increased significantly $(\mathrm{p}<0.05)$ with shorter standing times, lower self reported walking speeds, and

TABLE III - Physical activity and risk of hip fracture in 300 patients with hip fracture and 600 matched controls

\begin{tabular}{|c|c|c|c|c|c|c|c|c|c|c|}
\hline \multirow[b]{3}{*}{ Activity } & \multicolumn{5}{|c|}{ Women } & \multicolumn{5}{|c|}{ Men } \\
\hline & \multirow[b]{2}{*}{$\begin{array}{c}\text { No of } \\
\text { patients } \\
(\mathrm{n}=240)\end{array}$} & \multirow[b]{2}{*}{$\begin{array}{c}\text { No of } \\
\text { controls } \\
(n=480)\end{array}$} & \multicolumn{3}{|c|}{ Relative risk } & \multirow[b]{2}{*}{$\begin{array}{c}\text { No of } \\
\text { patients } \\
(n=60)\end{array}$} & \multirow[b]{2}{*}{$\begin{array}{c}\text { No of } \\
\text { controls } \\
(n=120)\end{array}$} & \multicolumn{3}{|c|}{ Relative risk } \\
\hline & & & $\begin{array}{c}\text { Non- } \\
\text { adjusted }\end{array}$ & Adjusted $\dagger$ & $\begin{array}{c}95 \% \\
\text { Confidence } \\
\text { interval }\end{array}$ & & & $\begin{array}{c}\text { Non- } \\
\text { adjusted }\end{array}$ & Adjusted $\dagger$ & $\begin{array}{c}95 \% \\
\text { Confidence } \\
\text { interval }\end{array}$ \\
\hline \multicolumn{11}{|c|}{ Standing time (mins/day): } \\
\hline None & 15 & 21 & $2 \cdot 9$ & $1 \cdot 6$ & 0.5 to 4.6 & 0 & 2 & & & \\
\hline 1. & 84 & 102 & $3 \cdot 1$ & $2 \cdot 9$ & 1.7 to 4.9 & 16 & 23 & 1.9 & $2 \cdot 1$ & 0.6 to 7.5 \\
\hline 30 - & 76 & 152 & 1.9 & $1 \cdot 8$ & 1.1 to 2.9 & 18 & 30 & 1.6 & 1.9 & 0.7 to 5.0 \\
\hline \multirow{2}{*}{\multicolumn{11}{|c|}{ Self reported walking speed: }} \\
\hline & & & & & & & & & & \\
\hline Very slow & 132 & 207 & $2 \cdot 4$ & $2 \cdot 6$ & $1 \cdot 3$ to $5 \cdot 2$ & 23 & 36 & 1.5 & $1 \cdot 6$ & 0.5 to 5.7 \\
\hline Easy pace & 46 & 114 & $1 \cdot 4$ & 1.5 & 0.7 to 3.0 & 17 & 34 & $1 \cdot 2$ & 0.9 & 0.3 to 2.9 \\
\hline Normal speed & 40 & 90 & 1.5 & 1.5 & 0.7 to $3 \cdot 1$ & 10 & 27 & 0.9 & 0.9 & 0.2 to 3.4 \\
\hline Brisk/fast & 22 & 68 & $1 \cdot 0$ & 1.0 & & 10 & 23 & $1 \cdot 0$ & $1 \cdot 0$ & \\
\hline \multicolumn{11}{|c|}{ Walking time (mins/day): } \\
\hline None & 126 & 236 & $1 \cdot 4$ & $0 \cdot 8$ & 0.4 to 1.8 & 24 & 43 & $2 \cdot 5$ & $3 \cdot 4$ & 0.8 to 15.1 \\
\hline $1-$ & 79 & 154 & $1 \cdot 3$ & 0.9 & 0.4 to 2.0 & 23 & 35 & $2 \cdot 8$ & $2 \cdot 7$ & 0.7 to 10.8 \\
\hline 30 & 21 & 57 & 0.9 & 0.8 & 0.3 to 2.0 & 7 & 16 & 1.9 & $4 \cdot 2$ & 0.8 to 23.1 \\
\hline$\geqslant 60$ & 14 & 33 & $1 \cdot 0$ & 1.0 & & 6 & 26 & 1.0 & $1 \cdot 0$ & \\
\hline \multicolumn{11}{|c|}{ Muscle loading activity (frequency): } \\
\hline Never & 89 & 131 & $2 \cdot 0$ & $1 \cdot 7$ & $1 \cdot 0$ to $3 \cdot 1$ & 13 & 22 & $4 \cdot 6$ & $2 \cdot 5$ & 0.5 to 13.2 \\
\hline Less than weekly & 63 & 112 & $1 \cdot 6$ & $1 \cdot 7$ & $1 \cdot 0$ to $3 \cdot 1$ & 19 & 19 & $7 \cdot 9$ & $5 \cdot 6$ & 1.3 to 23.9 \\
\hline Weekly to daily & 42 & 117 & 0.9 & $1 \cdot 0$ & 0.6 to 1.8 & 18 & 32 & $3 \cdot 5$ & 3.6 & 1.0 to 12.9 \\
\hline Several times a day & 46 & 120 & $1 \cdot 0$ & $1 \cdot 0$ & & 10 & 47 & $1 \cdot 0$ & 1.0 & \\
\hline \multicolumn{11}{|c|}{ Productive activity (hours/week): } \\
\hline None & 66 & 212 & $2 \cdot 7$ & $2 \cdot 0$ & $1 \cdot 1$ to 3.7 & 10 & 13 & $2 \cdot 7$ & $2 \cdot 4$ & 0.5 to 12.0 \\
\hline $1-$ & 52 & 105 & 3.4 & $3 \cdot 3$ & 1.9 to 5.7 & 15 & 13 & $4 \cdot 2$ & $3 \cdot 8$ & $1 \cdot 1$ to 13.6 \\
\hline $3-$ & 66 & 77 & 1.8 & 1.8 & 1.0 to 2.9 & 14 & 31 & 1.8 & $3 \cdot 2$ & 0.9 to 11.3 \\
\hline$\geqslant 5$ & 56 & 86 & 1.0 & 1.0 & & 21 & 63 & 1.0 & 1.0 & \\
\hline
\end{tabular}

*Information was not available for all subjects.

†Adjusted for body mass index, smoking, alcohol, stroke, and steroid treatment. 
TABLE IV-Mean grip strength $(\mathrm{kg})(95 \%$ confidence interval) by age and sex of patients with hip fracture and controls

\begin{tabular}{|c|c|c|c|c|}
\hline \multirow[b]{2}{*}{ Age (years) } & \multicolumn{2}{|c|}{ Women } & \multicolumn{2}{|c|}{ Men } \\
\hline & $\begin{array}{c}\text { No of patients } \\
\quad(n=238)\end{array}$ & $\begin{array}{l}\text { No of controls } \\
\quad(n=479)\end{array}$ & $\begin{array}{l}\text { No of patients } \\
\quad(n=60)\end{array}$ & $\begin{array}{l}\text { No of controls } \\
\quad(n=120)\end{array}$ \\
\hline$<55$ & $30 \cdot 0(16 \cdot 9$ to $43 \cdot 1)$ & $27 \cdot 4(24.0$ to 30.8$)$ & $40 \cdot 5(27 \cdot 2$ to $53 \cdot 8)$ & $39.9(33.3$ to 46.5$)$ \\
\hline $55-$ & $23 \cdot 7(18 \cdot 2$ to $29 \cdot 2)$ & $23 \cdot 8(20 \cdot 5$ to $27 \cdot 0)$ & $33.8(25.7$ to 41.8$)$ & $42.6(36.9$ to 48.3$)$ \\
\hline 65. & $18 \cdot 3(16 \cdot 4$ to $20 \cdot 3)$ & $20.9(19.6$ to 22.2$)$ & $27 \cdot 2(22.0$ to $32 \cdot 4)$ & $33.5(29.4$ to 37.6$)$ \\
\hline $75-$ & $13.5(12.4$ to 14.5$)$ & $17.6(16.8$ to 18.4$)$ & $22 \cdot 1(19 \cdot 1$ to $25 \cdot 1)$ & $25.4(22.6$ to 28.2$)$ \\
\hline$>84$ & $10 \cdot 7(9.8$ to 11.6$)$ & $13 \cdot 0(12 \cdot 1$ to $13 \cdot 8)$ & $15.4(11.5$ to $19 \cdot 2)$ & $20 \cdot 5(16 \cdot 1$ to $24 \cdot 9)$ \\
\hline
\end{tabular}

TABLE V-Distribution of grip strength and risk of hip fracture in patients with hip fracture and controls ${ }^{\star}$

\begin{tabular}{|c|c|c|c|c|c|c|}
\hline \multirow[b]{2}{*}{$\begin{array}{l}\text { Fifths of the } \\
\text { distribution of } \\
\text { grip strength }(\mathrm{kg})\end{array}$} & \multirow[b]{2}{*}{$\begin{array}{c}\text { No of } \\
\text { patients }\end{array}$} & \multirow[b]{2}{*}{$\begin{array}{c}\text { No of } \\
\text { controls }\end{array}$} & \multicolumn{4}{|c|}{ Relative risk } \\
\hline & & & Non-adjusted & $\begin{array}{c}95 \% \\
\text { Confidence } \\
\text { interval }\end{array}$ & Adjusted $\dagger$ & $\begin{array}{c}95 \% \\
\text { Confidence } \\
\text { interval }\end{array}$ \\
\hline \multicolumn{7}{|c|}{ Women } \\
\hline$<10$ & 60 & 64 & 4.9 & $2 \cdot 7$ to 9.0 & $2 \cdot 7$ & 1.4 to 5.5 \\
\hline $10-$ & 64 & 82 & $4 \cdot 3$ & $2 \cdot 4$ to $7 \cdot 7$ & $3 \cdot 1$ & 1.6 to 5.9 \\
\hline 14 & 51 & 99 & $2 \cdot 5$ & 1.4 to 4.5 & $1 \cdot 7$ & 0.9 to 3.2 \\
\hline 18 & 33 & 116 & $1 \cdot 3$ & 0.7 to 2.3 & $1 \cdot 0$ & 0.5 to 1.8 \\
\hline$\geqslant 23$ & 30 & 118 & $1 \cdot 0$ & & 1.0 & \\
\hline \multicolumn{7}{|c|}{ Men } \\
\hline$<18$ & 15 & 20 & 4.9 & 1.3 to 18.9 & 1.9 & 0.4 to 9.5 \\
\hline $18-$ & 16 & 17 & $6 \cdot 7$ & $1 \cdot 7$ to $26 \cdot 1$ & $2 \cdot 4$ & 0.5 to 12.0 \\
\hline $25-$ & 13 & 27 & $2 \cdot 1$ & 0.7 to 6.7 & 1.4 & 0.4 to 5.5 \\
\hline $31-$ & 7 & 28 & 0.9 & 0.3 to $3 \cdot 3$ & $0 \cdot 7$ & $0 \cdot 2$ to $3 \cdot 1$ \\
\hline$\geqslant 39$ & 9 & 28 & $1 \cdot 0$ & & $1 \cdot 0$ & \\
\hline
\end{tabular}

*Information was not available for all subjects

tAdjusted for body mass index, smoking, alcohol, stroke, and steroid treatment.

TABLE VI - Dietary calcium intake and risk of hip fracture in patients with hip fracture and controls

\begin{tabular}{|c|c|c|c|c|c|c|}
\hline \multirow[b]{2}{*}{$\begin{array}{l}\text { Fifths of the } \\
\text { distribution of } \\
\text { calcium intake } \\
(\mathrm{mg} / \text { day })\end{array}$} & \multirow[b]{2}{*}{$\begin{array}{c}\text { No of } \\
\text { patients }\end{array}$} & \multirow[b]{2}{*}{$\begin{array}{c}\text { No of } \\
\text { controls }\end{array}$} & \multicolumn{4}{|c|}{ Relative risk } \\
\hline & & & Non-adjusted & $\begin{array}{c}95 \% \\
\text { Confidence } \\
\text { interval }\end{array}$ & Adjusted ${ }^{\star}$ & $\begin{array}{c}95 \% \\
\text { Confidence } \\
\text { interval }\end{array}$ \\
\hline \multicolumn{7}{|c|}{ Women } \\
\hline$<433$ & 47 & 97 & $1 \cdot 0$ & 0.6 to 1.6 & $1 \cdot 2$ & 0.7 to 2.2 \\
\hline 433 & 51 & 93 & $1 \cdot 1$ & 0.7 to 1.8 & 1.4 & 0.8 to 2.5 \\
\hline 567. & 48 & 96 & 1.0 & 0.6 to 1.7 & $1 \cdot 1$ & 0.6 to 2.0 \\
\hline $684-$ & 47 & 97 & $1 \cdot 0$ & 0.6 to 1.6 & $1 \cdot 2$ & 0.7 to 2.1 \\
\hline$\geqslant 838$ & 47 & 97 & 1.0 & & 1.0 & \\
\hline \multicolumn{7}{|c|}{ Men } \\
\hline$<500$ & 15 & 21 & $4 \cdot 6$ & 1.4 to 15.0 & $6 \cdot 2$ & $1 \cdot 3$ to $29 \cdot 7$ \\
\hline $500-$ & 14 & 22 & $4 \cdot 0$ & 1.2 to 13.0 & $5 \cdot 8$ & $1 \cdot 1$ to $29 \cdot 0$ \\
\hline 668 & 14 & 22 & $3 \cdot 6$ & 1.2 to 11.1 & $3 \cdot 3$ & 0.8 to 14.1 \\
\hline $841-$ & 12 & 24 & $3 \cdot 2$ & 0.9 to 11.3 & $6 \cdot 2$ & 1.2 to 32.7 \\
\hline$\geqslant 1041$ & 5 & 31 & $1 \cdot 0$ & & $1 \cdot 0$ & \\
\hline
\end{tabular}

^Adjusted for body mass index, smoking, alcohol, stroke, and steroid treatment.

less frequent muscle loading and productive activity. Similar increases in risk among men were associated with less activity. The number of men was smaller, and the increases were not significant. Body mass index, cigarette smoking, alcohol consumption, history of stroke, and use of corticosteroids (table II) were thought to be possible confounding variables - that is, independently associated with physical activity and hip fracture. We therefore examined the relation between physical activity and the risk of fracture after adjusting for these variables (table III), but this did not greatly affect the trend.

\section{MUSCLE STRENGTH}

Table IV shows the variation of strength of grip with age and sex. It fell sharply with age in both patients in the study group and controls. The mean strength in each age group was greater in men than in women. We calculated the risk of fracture for men and women in each fifth of the distribution of grip strength (table V). There was an almost fivefold increase in risk between the lowest and highest fifths of strength. This increase was significant for both women $(\mathrm{p}<0.001)$ and men $(p=0.001)$. The risk of fracture remained significantly $(p<0.001)$ increased in women with reduced grip strength after allowing for all the confounding variables, and though this increased risk remained in men, it was not significant $(p=0 \cdot 20)$. After we allowed for age and sex, grip strength was significantly $(p<0.01)$ related to each of the five indices of activity in both patients in the study group and controls.

\section{CALCIUM INTAKE}

The mean daily calcium intake of the controls was $651 \mathrm{mg}$ for women (interquartile range $467-799 \mathrm{mg}$ ) and $843 \mathrm{mg}$ for men (interquartile range $560-1042 \mathrm{mg}$ ). Table VI shows the relative risks of fracture in women and men in each fifth of the distribution of calcium intake. Among women there was no change in risk with increasing calcium intake. In men there was a fall in risk with increasing intake. This trend did not remain after adjusting for the five confounding variables, but the adjusted risk among men with the highest intakes, more than $1041 \mathrm{mg} /$ day, remained significantly lower than that among the rest.

\section{Discussion}

The results of this study suggest that inactivity and muscle weakness are associated with an increased risk of hip fracture in elderly people. In both sexes less physical activity as measured by four of the five indices was associated with a doubling of risk of fracture (table III). There were fewer men than women, however, so estimates for men were less certain and not significant at $\mathrm{p}=0.05$.

Selecting people with mental test scores of six or more led to the exclusion of around one third of patients but fewer controls. Although patterns of activity are likely to be different in people with low mental test scores, we think it unlikely that this would create a false association between inactivity and risk of fracture.

The risk of fracture increased steeply with lower strength of grip in both sexes. Part of this association may be explained by loss of strength as a result of fracture. Strength of grip, however, correlated with reported levels of physical activity. The differences in grip strength between patients and controls were therefore unlikely to be solely a consequence of fracture. Activity and muscle strength could protect against hip fracture either by preserving bone mass or by reducing the risk and severity of falls. Severa reports suggest an association between exercise and bone mass. ${ }^{9-12} \mathrm{~A}$ relation between activity, muscle strength, and falling has been found in a national sample of 1000 elderly people in Britain. ${ }^{13}$ Lower levels of both mobility and grip strength were associated with an increased frequency of reported falls.

Among women there was no relation between the risk of fracture and the intake of calcium. Among men, after we had adjusted for confounding variables, the risk was lower in those in the highest fifth of calcium intake. Evidence that either hip fractures or osteoporosis are related to dietary calcium intake is inconsistent. A comparison of two populations in Yugoslavia showed a higher incidence of hip fracture in the one with the lower calcium intake. ${ }^{14}$ Two casecontrol studies, however, did not show associations between calcium intake and the risk of fracture. ${ }^{1516}$ Studies on metabolic balance show a drop in the efficiency of mechanisms that maintain calcium balance with increasing age. This is particularly noticeable in postmenopausal women. ${ }^{17}$ Trials of calcium supplementation, however, have shown little, if any, beneficial effect on the rate of bone loss. ${ }^{18}{ }^{19}$ Our results suggest that in elderly women in southern Britain low calcium intake is not a risk factor for hip fracture. In men, however, our results support a protective effect with a calcium intake above $1 \mathrm{~g}$ a day, an intake recorded in only $7 \cdot 5 \%$ of the women studied.

We conclude that physical inactivity and muscle 
weakness are both associated, independently of other influences, with an increased risk of hip fracture in elderly people. This points to the importance of maintaining physical activity in the day to day lives of old people.

We thank the consultants and staff of the department of orthopaedic surgery, Southampton General Hospital, and the general practitioners of the Southampton health district; $\mathrm{Mrs}$ $M$ Mitchell and Mrs S Underwood interviewed some of the patients; Mr G Butcher helped in selecting controls; Dr E J Bassey and Dr H Dallosso of the department of physiology and pharmacology, University of Nottingham Medical School, helped with the method of assessing physical activity; and Dr W J Boyce, Northampton health district, advised on the design of the study.

1 Cooper C, Barker DJP, Morris J, Briggs RSJ. Osteoporosis, falls, and age in fracture of the proximal femur. Br Med F 1987;295:13-5.

2 Anonymous. Consensus Development Conference: prophylaxis and treatment of osteoporosis. Br Med J 1987;295:914-5.

3 Kelsey JL, Hoffman S. Risk factors for hip fracture. $N$ Engl $\mathcal{f}$ Med 1987;316:404-6.

4 Quereshi KN, Hodkinson HM. Evaluation of a ten question mental test in the institutionalised elderly. Age Ageing 1974;3:152-7.

5 Dallosso HM, Morgan K, Bassey EJ, Fentem PH, Arie TDH. Levels of customary physical activity among the old and very old living at home. I E pidemiol Community Health 1988;42:121-7.

6 Department of Health and Social Security. A nutrition survey of the elderly. London: HMSO, 1972. (Report on health and social subjects No 3.)
7 Nelson M, Hague GF, Cooper C, Bunker VW. Calcium intake in the elderly validation of a dietary questionnaire. Joumal of Human Nutrition and Dietetics 1988;1:115-27.

8 Breslow NE, Day NE. Conditional logistic regression for matched sets. In: Breslow NE, Day NE, eds. Statistical methods in cancer research. Volume 1 . The analysis of case control studies. Lyons: International Agency Research on The analysis of case con

9 Krolner B, Toft B. Vertebral bone loss: an unheeded side effect of therapeutic bed rest. Clin Sci 1983;64:537-40.

10 Mack PB, LaChance PA, Vose GP, Vogt FB. Bone demineralisation of foo and hand of Gemini-Titan IV, V and VII astronauts during orbital flights. American fournal of Roentgenology, Radium Therapy and Nuclear Medicin 1967;100:503-11

11 Huddleston AL, Rockwell D, Kulund DN, Harrison RB. Bone mass in lifetime tennis athletes. FAMA 1980;244:1107-9.

12 Chow R, Harrison JE, Notarius CE. Effect of two randomised exercise programmes on bone mass of healthy postmenopausal women. $\mathrm{Br} \mathrm{Med} \mathcal{F}$ 1987;295:1441-4.

13 Wickham C, Cooper C, Margetts BM, Barker DJP. Muscle strength, activity, housing and the risk of falls in the elderly. Age Ageing (in press.)

14 Matkovic V, Kostial K, Simonivoc I, Buzina R, Brodarec A, Nordin BEC. Bone status and fracture rates in two regions of Yugoslavia. Am $\mathcal{f}$ Clin Nutr 1979;32:540-9.

15 Baker MR. The epidemiology and aetiology of femoral neck fracture. Newcastle upon Tyne: University of Newcastle upon Tyne, 1980. (MD Dissertation.) 16 Wootton R, Brereton PJ, Clark MB, Hesp R, Hodkinson HM, Klenerman L. Fractured neck of femur in the elderly: an attempt to identify patients a risk. Clin Sci 1979;57:93-101.

17 Heaney RP, Recker RR, Saville PD. Menopausal changes in calcium balance performance. F Lab Clin Med 1978;92:953-64

18 Horsman A, Gallagher JC, Simpson M, Nordin BEC. Prospective trial of oestrogen and calcium in postmenopausal women. $\mathrm{Br}$ Med $\mathrm{f}$ 1977;ii:789-92.

19 Riis B, Thomsen K, Christiansen C. Does calcium supplementation prevent postmenopausal bone loss? A double blind, controlled clinical study. $N \mathrm{Engl}$ f Med 1987;316:173-7.

(Accepted 20 September 1988)

\section{Effects of withdrawal of co-danthramer on use of laxatives in a district general hospital}

\author{
D R Upton, J K Taylor, G K T Holmes, \\ J W Poston
}

\section{Medicines Research Unit, District Pharmacy, Derbyshire Royal \\ Infirmary, Derby DE1 2QY \\ D R Upton, MRPHARMS, staff} pharmacist

J K Taylor, MRPHARMS, resident pharmacist

G K T Holmes, FRCP, consultant physician

Welsh School of Pharmacy, University of Wales Institute of Science and Technology, Cardiff CF1 3NU

$\mathrm{J}$ W Poston, PHD, associate director

Correspondence to: $\mathrm{Mr}$ Upton.
In March 1987, after new evidence that long term administration of high doses of danthron was associated with tumours in rodents, the manufacturers of co-danthramer (Dorbanex and Dorbanex Forte) surrendered product licences for these preparations. ${ }^{1}$ At this hospital co-danthramer was used extensively as a result of routine prescribing and a policy permitting nursing staff to administer up to three doses of the liquid laxative without a prescription, a ruling also applied to senna tablets. After the withdrawal the drugs and therapeutics subcommittee issued guidance that treatment of constipation should be based on dietary or prescribed fibre, though if a stimulant laxative was necessary senna provided a suitable alternative to co-danthramer. Senna syrup replaced co-danthramer as the liquid laxative to be given by nurses. Lactulose was discouraged as a first line laxative, being unsuitable for administration as required and fairly expensive. This guidance was supplemented by a bulletin from the district drug information centre.

We looked at use of laxatives before and after the withdrawal of co-danthramer and assessed changes in view of the recommendations made.

\section{Method and results}

Use of laxatives by inpatients was measured from data on the pharmacy computer on issues to the wards. This information was converted to defined daily doses, a unit defined as the assumed average daily dose of the drug when used for its main indication in adults. ${ }^{2}$ The values used were determined after consultation with colleagues. To relate defined daily dose to patient numbers we determined the number of occupied bed days recorded for the hospital and then calculated the number of defined daily doses used per 100 occupied bed days. ${ }^{34}$ Use of laxatives was compared for two periods of six months (April to September) in 1986 and 1987, one before and the other after the withdrawal of co-danthramer. Financial data were also considered to assess the implications in terms of cost of changing patterns of use of laxatives.

The results confirmed that co-danthramer liquid was the most used laxative preparation in 1986 (at 10.9 defined daily doses per 100 occupied bed days), accounting for $37 \%$ of all laxative use, with lactulose and ispaghula sachets ranked second and third (table).

Use of laxatives from April to September, 1986 and 1987. Values are expressed as defined daily doses per 100 occupied bed days

\begin{tabular}{lrr}
\hline Laxative & 1986 & 1987 \\
\hline Co-danthramer liquid & $10 \cdot 9$ & \\
Lactulose & $6 \cdot 4$ & 10.9 \\
Ispaghula sachets & $5 \cdot 5$ & $4 \cdot 4$ \\
Glycerin suppositories & $2 \cdot 2$ & $2 \cdot 4$ \\
Senna tablets & $1 \cdot 3$ & 3.9 \\
Senna syrup & $0 \cdot 1$ & $5 \cdot 9$ \\
Phosphate enemas & $0 \cdot 7$ & $0 \cdot 8$ \\
Sodium citrate enemas & $0 \cdot 6$ & 0.9 \\
Bisacodyl suppositories & $0 \cdot 2$ & 0.6 \\
Docusate sodium 100 mg tablets & $0 \cdot 2$ & 0.7 \\
Other preparations & 0.6 & 0.3 \\
\hline
\end{tabular}

The total use of laxatives rose from $29 \cdot 3$ defined daily doses per 100 occupied bed days in 1986 to $31 \cdot 3$ in 1987, when lactulose was the most commonly used agent. The use of ispaghula fell in 1987 while use of senna preparations, particularly the syrup, showed a pronounced rise. Expenditure on laxatives rose considerably after the withdrawal of co-danthramer, from $£ 1986$ for the six months in 1986 to $£ 3274$ for the corresponding period in 1987.

\section{Comment}

The total use of laxatives increased by 7\% from 1986 to 1987 , whereas expenditure rose by $65 \%$. Even allowing for inflation and price rises, this suggests that costs increased because expensive preparations were used rather than because of a large increase in use. 